\title{
Nom nom nom: Two years of Applied Food Science and Engineering as a chemical engineering elective
}

Dr. Margot A Vigeant, Bucknell University

Dr. Margot Vigeant is an associate professor of chemical engineering at Bucknell University and a dedicated 'foodie.' She was happy to combine both passions in the development and execution of this course. 


\title{
Nom nom nom: Two Years of Applied Food Science and Engineering as a Chemical Engineering Elective
}

\begin{abstract}
Food and related commercial and consumer products are a significant industrial sector, regularly accounting for the employment of 15-20\% of our graduating class. Inspired by this and an interest in food and food science among faculty and students in general, we developed a course in Applied Food Science and Engineering, taught for the first time in Fall 2011 and then again in Fall 2012.

The course is a four-credit upper level elective, taught in a problem-based format. Class time is scheduled as two two-hour blocks to allow integration of class and lab in a flexible manner. Course objectives include students' attaining a level of familiarity with molecular scale cooking and preservation processes as well as with the large-scale unit operations used to implement them industrially. Students are also expected to engage with the extensive regulatory, political, and ethical environment surrounding food production and policy. The five problems on which the course is based span key elements of food chemistry such as reduction, emulsification, crystallization, pasteurization, and fermentation. The course concludes with a final "free- choice" project where students propose a new product not currently available in stores, and also a just for fun 'Iron Chef'-style competition. Student work demonstrates that the course objectives are being achieved.
\end{abstract}

\section{Background}

Motivation

Students' interest in the technical aspects of food is at a peak, inspired by the mainstream popularity of food science shows such as Good Eats and techie food blogs and Pinterest sites. Not only is there general interest in the chemical mechanisms behind "typical" food, but molecular gastronomy as a high-end cooking approach (as seen in the groundbreaking el Buli and Alinea restaurants) is generating significant interest. While the fraction of chemical engineering graduates going into the food and consumer products sector has held relatively constant at 10-20\% for decades (1), at our institution the fraction of our graduates heading into such industry has increased from slightly below the national average to slightly greater during the past decade. At $15-25 \%$ of our graduates, the fraction is comparable to that going into pharmaceutical/bioprocess and greater than that heading into polymer-related industries, both areas with well established electives.

While students' interest in food science can be somewhat assuaged through television, YouTube, and popular books, food product engineering and food process engineering are somewhat less addressed in these venues. Many Agriculture-based state schools have programs in food science and food engineering. However, their courses are often intended primarily for majors and are not available at all institutions. Our course, Applied Food Science and Engineering (AFS\&E) was conceived as a response to student and faculty interest, and inspired both by Rowan's Principles of Food Engineering course 
(2) and by our Applied Surface Chemistry course (previously taught by the author with a heavy emphasis on food-related examples).

AFS\&E is a hybrid between food science / food chemistry and food process/product engineering. This blend was selected for several reasons. In reviewing introductory textbooks for Food Engineering, we found that they cover ideas already familiar from Chemical engineering core courses (such as mass and energy balances, fluid mechanics, pump sizing, heat exchanger design, separations, process control (3)) but in a food industry context. The gap in our students' knowledge, therefore, was in examples of these processes as applied to food, and in the particular chemical, regulatory, and cultural environment that makes process design choices here distinct from choices in the chemical industry. Our Chemistry Department has offered occasional courses on food chemistry, so the current course balance seeks to address students' interest in this area while providing an engineering context relevant for their future careers.

Goals

The instructor identified five concept areas that would be the foundational elements of AFS\&E, shown in Table 1.

Table 1: Concept Areas for Applied Food Science and Engineering

\begin{tabular}{|l|l|}
\hline Concept Area & Examples \\
\hline Chemical reactions in cooking & $\begin{array}{l}\text { Maillard, caramelization, denaturation, } \\
\text { ripening, browning, cross-linking gelation; } \\
\text { includes developing an understanding of } \\
\text { chemical components of foods such as } \\
\text { starch, sugar, protein, etc }\end{array}$ \\
\hline Food preservation & $\begin{array}{l}\text { Pasteurization, fermentation, water activity, } \\
\text { aseptic packaging, chemical preservation }\end{array}$ \\
\hline Surface chemistry & $\begin{array}{l}\text { Emulsification, foaming, crystallization, } \\
\text { surfactants }\end{array}$ \\
\hline Processes at scale & $\begin{array}{l}\text { large scale evaporation, preservation, heat } \\
\text { exchangers, etc. }\end{array}$ \\
\hline Regulation, safety, culture, and ethics & $\begin{array}{l}\text { USDA, FDA, SOPs, CGMPs, CFR } \\
\text { standards and definitions, terrioir, } \\
\text { differences in US / European standards and } \\
\text { labeling, Kosher, etc. }\end{array}$ \\
\hline
\end{tabular}

This sub-set of possible concepts serves as the core of what a graduate should be minimally expected to understand as well as a foundation for future learning. The overall goals for the course were that each student would have a chance to apply these concepts in a variety of settings and in the creation of a variety of products (see Appendix A). It was also an expectation that not only would students be able to verbally explain and solve numerical problems related to these concepts, but that they would be able to execute and create recipes based upon them as well. 
Students were required to purchase McGee's On Food and Cooking as their course text (4), which was used as a reference throughout the course. The instructor relied on a number of technical and popular books on food science throughout the course (5-25), and also worked with a number of journal articles from the food science and processing literature as questions came up in class.

\section{Setting}

AFS\&E is a upper level elective, open primarily to senior and graduate chemical engineering majors. The course is also open to juniors and other engineering / science majors when space is available. It is a four-credit course, meeting twice weekly for two hours. This block schedule was adopted in order to allow flexibility in the use of class time, as described below. It is a "permission" course, having no formal pre- or corequisites listed, although the course relies on students' coursework in mass and energy balances, heat transfer, thermodynamics, and chemistry to a significant extent.

We wanted to have a food-safe laboratory available as part of this course so that students could not only prepare and assess food products, but also taste what they had made. We strongly suggest that anyone wishing to bring this course to their campus do the same, and spend some time discussing the requirements of such a laboratory space with their Safety Officer and University Counsel. After extensive discussion, it was determined that no existing laboratory spaces could be converted to "food safe", and therefore the "lab" became two rolling carts and a small refrigerator. Cooking essentials were stored on one cart, including two toaster ovens, two food-grade hot plates, a microwave, fire extinguisher, bowls etc. The other cart was used as a pantry, with refrigerated items residing in a food-safe fridge stored in the classroom.

Food safety procedures covering personal and classroom hygiene and practices were distributed to and signed by each student. At the request of counsel, students could not be required to taste anything prepared in or for class. Counsel also required that the class avoid working with raw meats. Students signing up for the course provided a signed release recognizing that they would be expected to handle and prepare food in this course and to disclose any allergies or religious / cultural food prohibitions. In practice, this was seldom a problem.

\section{Course Design and Structure}

The complex nature of the subject matter combined with the relative ease of connecting the material to 'real world' experiences and the instructor's desire to make experimentation a significant portion of the course suggested a problem-based learning format could be a successful pedagogical approach (26). The course is therefore broken into six segments, each of which is driven by a particular "problem". A summary of the problems employed in the class are shown in Table 2. The problems were chosen to highlight one or more of the concept areas given in Table 1, but intentionally do not have a one-to-one mapping. 
Table 2: Problems used in the course

\begin{tabular}{|l|l|}
\hline \multicolumn{1}{|c|}{ Problem } & \multicolumn{1}{|c|}{ Description } \\
\hline Me want cookie & $\begin{array}{l}\text { Propose a small scale "gourmet", "healthy" cookie process } \\
\text { (2011) } \\
\text { Replicate the "Thin Mint" with a significant improvement at } \\
\text { small scale (2012) }\end{array}$ \\
\hline Tomato, tomahto & $\begin{array}{l}\text { Propose a formulation or process improvement for large scale } \\
\text { sauce manufacture that allows the consumer price to rise by only } \\
\text { a small fraction when the price of tomatoes doubles }\end{array}$ \\
\hline Fried! & $\begin{array}{l}\text { Propose a shop-scale process and formulation for donuts that are } \\
\text { "baked, not fried" (2011) } \\
\text { Propose a large-scale process and formulation for "baked, not } \\
\text { fried" potato "chips" (2012) }\end{array}$ \\
\hline Drinking Problem & $\begin{array}{l}\text { Each team researched and presented the process, market, and a } \\
\text { process or product improvement for a particular beverage such } \\
\text { as coffee, tea, beer, energy drinks, wine, etc. }\end{array}$ \\
\hline Sweet! & $\begin{array}{l}\text { Propose a shelf-stable formulation and process for fudge at } \\
\text { medium scale (2011) } \\
\text { Propose a shelf-stable formulation and process for true caramel } \\
\text { (2012) }\end{array}$ \\
\hline $\begin{array}{l}\text { Entrepreneurial } \\
\text { Freestyle }\end{array}$ & $\begin{array}{l}\text { Identify a food that the student team likes but is not widely } \\
\text { available in the grocery store. Propose a formulation and process } \\
\text { for this product. }\end{array}$ \\
\hline
\end{tabular}

The syllabus is included as Appendix A.

Each problem took about two weeks to solve. As a first step, student teams (two students per team) were required to create and document an initial food product to address the problem, and also to generate a list of questions based on the problem. Students used their dorm or apartment kitchens in order to accomplish this initial step. Then class time was spent addressing the questions posed by students through lecture, discussion, reading, and/or experiment. At the end of the two week period, students turned in a memo containing their final solution as well as a notebook containing the answers to all questions posed during that problem. 


\begin{tabular}{|c|}
\hline $\begin{array}{l}\text { Problem 2:Tomato, Tomahto } \\
\text { Out: } 9 / 5 / 2012 \text { Due: (initial) } 9 / 10 / 12 \text {; final } 9 / 21 / 12 \\
\text { Problem Statement: } \\
\text { The mid-western part of the United States has suffered a drought this year of historic } \\
\text { proportions. Due to this, the price of many foods, including tomatoes has increased. Your } \\
\text { company, which produces all-natural tomato-based pasta sauces, cannot raise the price of } \\
\text { sauce more than } 20 \% \text { without negatively impacting the customer base. Sauce is currently } \\
\text { made in production-scale batches of } 1,000 \text { gallons by traditional (albeit large-scale) } \\
\text { evaporation-based methods. Recommend recipe, process, and/or product changes that will } \\
\text { allow the company to maintain profitability while preserving flavor, consistency, and cost } \\
\text { within acceptable parameters. Note you must first benchmark the process, formulation, and } \\
\text { economics of "typical" sauce in order to make substantive recommendations for this } \\
\text { problem. } \\
\text { Deliverables: }\end{array}$ \\
\hline $\begin{array}{l}\text { - Initial report (see below) } \\
\text { - Many questions (what do you need to know in order to solve this?)-post these on } \\
\text { Moodle by 9am on Monday morning! } \\
\text { - Solutions to those questions (research, lecture, experiment.....) - answered in modified } \\
\text { "notebook" format (appendix to final report). }\end{array}$ \\
\hline $\begin{array}{l}\text { + Final report including the following - formulation (i.e. recipe); raw materials specificati } \\
\text { and costs; process flow diagram; equipment specifications; packaging requirements and c } \\
\text { Memo text must demonstrate that all requirements are met, including taste of product, } \\
\text { process changes, and profitability at target price. Report will be accompanied by a } 5 \\
\text { minute or less sales pitch to be delivered by randomly selected / volunteer teams in-clas }\end{array}$ \\
\hline $\begin{array}{l}\text { Notes on initial / final reports: } \\
\text { For this problem, your audience is the "boss" of the sauce company. So while taste is very } \\
\text { important, process aspects are also important and you may assume they can be explained at } \\
\text { an engineering-level of understanding. } \\
\text { With your team, make sauce and create an initial report (see "initial report" format } \\
\text { document). You may use a recipe, and please work at a small scale, but specifically observe } \\
\text { the aspects of the process that are likely to be "expensive" at large scale. That is, the sauce } \\
\text { you make may either be a model for "traditional" process sauce (base case, you need to } \\
\text { observe opportunities for saving money) or it may be a less-expensive model (trial for } \\
\text { solution, you need to point out how this saves money). } \\
\text { Generate a list of questions that you need Dr. Vigeant to address in order for you to be able } \\
\text { to solve your problem. Anticipated questions include ones about evaporation, heat transfer, } \\
\text { ingredient function, preservation, and packaging. As with all problems posed in this } \\
\text { course, some questions will be addressed }\end{array}$ \\
\hline
\end{tabular}

\section{Figure 1: A sample problem}

For example, the problem in Figure 1 asks students to propose either a process or ingredient change that allows the price of tomato-based pasta sauce to increase relatively 
little while the price of tomatoes increases significantly. Students attempted home-made tomato sauce, and a summary of their questions are shown in Table 3.

Table 3: Student Generated Questions

\begin{tabular}{|l|l|}
\hline \multicolumn{1}{|c|}{ Group } & \multicolumn{1}{c|}{ Question } \\
\hline Sauce & What does 'reduction' mean? \\
\cline { 2 - 3 } & $\begin{array}{l}\text { How does sauce 'thicken' - what does that mean, what are our options for } \\
\text { doing it? }\end{array}$ \\
\cline { 2 - 3 } & How is sauce emulsified / prevented from separating? \\
\cline { 2 - 2 } & \begin{tabular}{l} 
What are the impacts of heating / simmering time? \\
\cline { 2 - 2 } \\
What additives are commonly added to sauce, and what do they do? \\
(sugar, acidity in particular)
\end{tabular} \\
\cline { 2 - 2 } Process & $\begin{array}{l}\text { How are herbs incorporated at large scale? } \\
\text { process? }\end{array}$ \\
\cline { 2 - 3 } & What are the largest costs in sauce production? \\
\cline { 2 - 3 } & How and why is the sauce shelf-stable until we open it? \\
\hline
\end{tabular}

There was no truly "typical" class day in the two-week problem solving period. Each class period was devoted to answering one or more questions. To address these questions, the class used their text, internet resources, class lecture, and in-class experiment. For example, the second question in Table 3 on 'thickening' was addressed through an open-ended in-class experiment in which the class was provided with tomato juice and a large variety of possible thickeners, including corn-starch, gelatin, xanthan gum, and corn syrup among many others, and asked to determine which 'worked'. Students then developed and conducted experiments during class time and shared their results with the room. Class sessions were active and either involved experiments, problem-solving, or presentation of online research by students.

In the problem cited above, students were largely successful at producing home-made sauce before class. In working towards the project goal, they were also successful in addressing each of the questions raised; in addition to being graded on preliminary and final reports, students are also graded on a notebook containing the answers to all posted questions. In the final reports, three competitive solutions arose, all of which had their merits: make the sauce thinner / thicken it with an additive; bulk out the sauce with cheaper vegetables; sell a smaller jar. Readers may recognize that each of these solutions is at work in the grocery aisle already. Grading of the final report is based on both the quality of the solution and the quality of the documentation and reasoning that got the students there, and also (sometimes) on taste.

Alongside the problem solving, each student team gave a 15-minute mini-lecture twice during the semester. For the first, students selected processed food ingredients with which they were unfamiliar, and presented on the source, chemistry, history, and controversies about that ingredient. Students were also responsible for creating an informative handout for the class and conducting a class discussion about a controversy related to their ingredient, as well as answering class questions. Ingredients selected by 
students included soy lecithin, carmine, and monosodium glutamate. The second presentation was on a food-products company, with similar requirements. Students discussed McCormick, Kikkoman, and Groupe Dannon, for example.

\section{Discussion}

Qualitatively, the course was very well received. The course has been offered twice, in Fall 2011 and Fall 2012. Both course offerings enrolled students up to the course cap, 16 in 2011 and 14 in 2012. Within the course, students actively engaged in experimentation and problem solving whenever given the opportunity. No major revisions were made to course goals or structure between the first and second offerings of the course, as students successfully met all course outcomes, as evaluated by project performance. However, problem topics were shifted slightly (Table 2) between years 1 and 2, mostly to keep things fresh and to respond to questions posed by colleagues. That is, colleagues took note of the course, and started providing questions they had been wondering about, which we then incorporated into problems.

More quantitatively, course survey results based on the IDEA form indicate significant agreement by students that key course objectives are being met. On a 5-point Likert scale, students gave an average rating of 4.4 or above to the following: This course was successful at helping me a) gain factual knowledge b) learn fundamental principles c) learn to apply course material d) learn how to use resources to answer questions and e) acquire an interest in learning more. The statement "overall I rate this course as excellent" received an average 4.6 on the same scale. Student comments reflect their sense that the course was well designed "The experiments we did in class were a great way to see the theory we discussed come true"; "It was a great way to connect what we were learning to the everyday life of cooking.". The main criticism for the course was that it had no dedicated kitchen-laboratory space. 


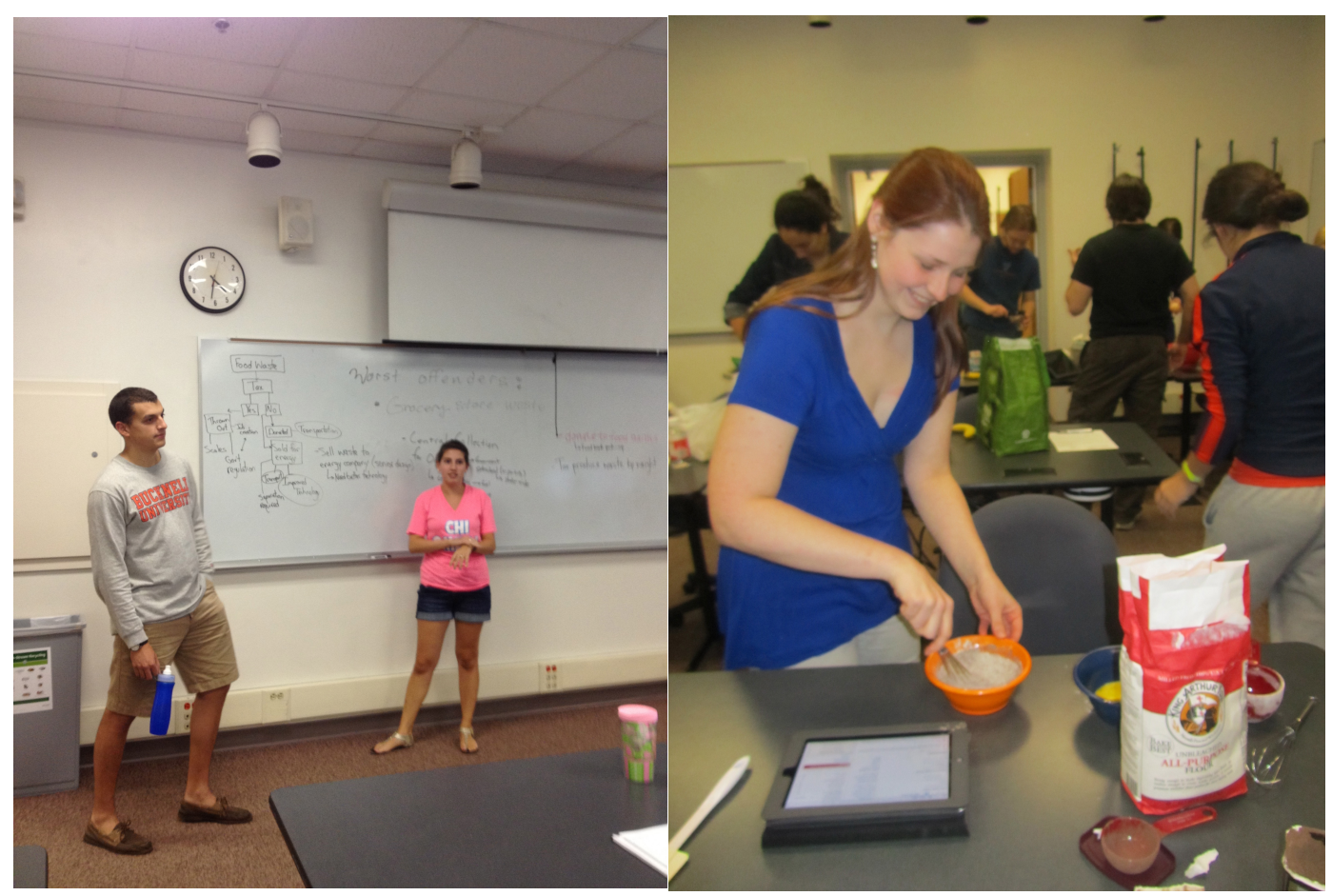

Figure 2: (Left) Students give an informal presentation of their in-class design project to reduce food waste from grocery stores to visiting author Jonathan Bloom. (right) Students prepare experimental recipes using Internet resources for reference.

The overall best evaluation of students' learning in the course is their creations for the final course "problem" - Entrepreneurial Freestyle Food. For this problem, each team was charged with proposing a novel processed food product not commonly available in grocery stores, along with sufficient supporting documentation to make the case that their idea is viable (formulation, process, market, etc). Out of the 15 teams, 14 truly novel products were proposed including toaster-funnel cakes, microwave cheesecake, DIY calzone kits, and an authentic Chinese fried rice for lunchboxes.

From the 2011 course offering, one student is now employed by Mars and another by Nestle, and the 2012 group has already received offers from both Mars, Hershey, and Hormel. Of the graduates at Mars and Nestle, each has noted that class-related concepts have been useful at work, which we feel is the best feedback we could possibly get.

While the course has received positive feedback thus far, there is room for improvement. One straightforward addition would be to incorporate field trips into the course; thus far, these have proved challenging to schedule both on the industrial and student side.

However, now that the course itself it better established, more instructor time should be available to coordinate such activities. A related stretch goal is to have the problems themselves proposed by local industry. This has not been attempted in part due to the limited 'laboratory' available for the class, but will hopefully be an option for future offerings as plans for addition of a kitchenette to one of the classrooms are underway.

\section{Bibliography}


1. Armstrong RC, Brennecke J, Butts S et al. How is the Discipline of Chemical Engineering Changing? AIChE Centennial 1908-2008. New York: AIChE Press; 2008.

2. Savelski, M.. A new chemical engineering senior elective course: Principles of Food Engineering. 2003; ASEE Nashville, TN: 2003.

3. Singh RP, Heldman DR. Introduction to Food Engineering. Boston: Academic Press; 2009

4. McGee H. On Food and Cooking. New York: Scribner; 2004

5. Amendola J, Rees N. Understanding Baking: The Art and Science of Baking. New York: John Wiley and Sons; 2003

6. Beckett ST. The Science of Chocolate. Cambridge, UK: Royal Society of Chemistry; 2008

7. Bloom J. American Wasteland. Cambridge, MA: Da Capo Press; 2010

8. Brillat-Savarin JA. The Physiology of Taste or Meditations on Transcendental Gastronomy. New York: Counterpoint; 1949

9. Brown A. I'm Just Here for the Food: Food + Heat = Cooking. New York: Harry N. Abrams; 2002

10. Coe SD, Coe MD. The True History of Chocolate. London: Thames and Hudson; 2007

11. Corriher SO. Cookwise: The Hows and Whys of Successful Cooking, the Secrets of Cooking Revealed. New York: William Morrow Cookbooks; 1997

12. Curtis W. And a Bottle of Run: A History of the World in Ten Cocktails. New York: Three Rivers Press; 2007

13. Ettlinger S. Twinkie, Deconstructed. New York: Hudson Street Press; 2007

14. McGee H. The Curious Cook: More Kitchen Science and Lore. New York: North Point Press; 1990

15. Myhrvold N, Young C, Bilet M. Modernist Cuisine: The Art and Science of Cooking. New York: The Cooking Lab; 2011

16. Pollan M. The Omnivore's Dilemma: A Natural History of Four Meals. New York: Penguin Books; 2006

17. Pringle P. Food, Inc.: Mendel to Monsanto - the Promises and Perils of the Biotech Harvest. New York: Simon and Schuster; 2003

18. Rudolph M. Pop Rocks: the Inside Story of America's Revolutionary Candy. Sharon, MA: Specialty Publishers; 2006

19. Ruhlman M. Ratio: The Simple Codes Behind the Craft of Everyday Cooking. New York: Scribner; 2009

20. Sokolov R. Why we eat what we eat: How Columbus Changed the way the World Eats. New York: Simon and Schuster; 1991

21. Tannahill R. Food in History. New York: Three Rivers Press; 1988

22. This H. Molecular Gastronomy: Ecploring the Science of Flavor. New York: Columbia University Press; 2006

23. Van Arsdale MB. Our Candy Recipes. New York: Macmillan; 1922

24. Visser M. Much Depends on Dinner. New York: Collier; 1986

25. Wolke RL. What Einstein Told His Cook. New York: W.W. Norton Company; 2002 
26. Prince M, Felder R. The many faces of inductive teaching and learning. Journal of College Science Teaching. 2007;36:14. 
CHEG 470: Special Topics in Chemical Engineering

Fall 2012: Applied Food Science and Engineering

Class: Dana 134, MW 3-5

Office hours: Open door policy, just stop by (check schedule on Google first to see if I am in). Email for appointment, and/or send an email or Google message any time.

\section{Text:}

On Food and Cooking by Harold McGee (note: this will be used as a reference; it is not a typical textbook.)

At least five "home works" during the semester will require cooking by student teams; it is expected that each team will take care of purchasing ingredients and equipment in a fair and consistent manner. Note that the Bucknell Bus is available to go shopping. Total investment in ingredients should not exceed $\$ 40$ per person over the course of the semester. Other useful books:

- I'm Just Here for the Food by Alton Brown

- Cookwise by Shirley Corrier

- FDA, CDC, EPA websites and documentation

\section{Course Goals:}

+ Become familiar with key aspects of the science of food preparation, characterization, preservation, and flavor. (ChemE program outcome 1.A "Content competency")

+ Explore how food products are prepared at the home, food-service, and industrial scales and how and why these processes differ. (ChemE program outcome 1.A "Content competency")

+ Design good solutions to several actual food-engineering and food-science problems. (ChemE program outcomes 1.B "Curricular integration"; 1.C "Analysis/Evaluation"; 2.A "Design"; 4.C "Independent learning”)

+ Attain familiarity with current business, regulatory, political, financial, and ethical implications of food and food production. Reflect on the historical bases for the current policies and situations. (ChemE program outcomes 3.B "Ethical/regulatory/ political"; 3.C "Process hazards";).

Note that being a better cook is not a specific outcome of this course, but it is anticipated as a by-product of the science and engineering!

\section{Course Format:}

This course will work in a "problem based" format (aka PBL). That means that we will start each segment with a particular food-engineering based problem, and then all content will flow from our joint search for a optimal solution to that problem. We are all going to be learning here! You may recognize this approach from Heat Transfer.

We are working this way because it is the best way to incorporate all aspects of food-based issues into your work and also the best way to direct the course content to our collective needs and interests. I will happily share the literature describing PBL with you upon request.

\section{Course Guidelines:}


+ Professional behavior is expected. This includes working in an atmosphere of mutual respect, as evidenced by behavior, attention, preparation, and communication. Specific examples of this behavior include

$+\quad$ Emailing Dr. Vigeant and teammates in advance of absences.

+ Minimizing distractions and distracting behavior during class time (texting, calling, etc)

$+\quad$ Coming to class prepared

$+\quad$ Acknowledging help from others and citing sources

$+\quad$ Working constructively with team members, giving and accepting feedback, doing your fair share of work.

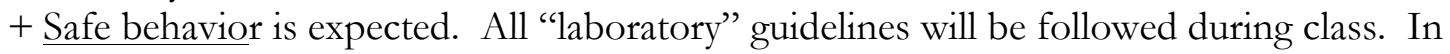
particular, sources of heat and hot liquids (including hot oil) will be common in class. Extreme care shall be taken at all times to avoid burns and fires.

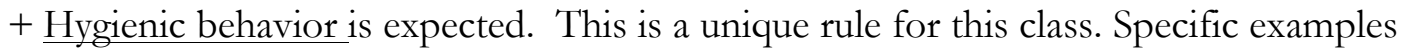
include:

$+\quad$ Washing and cleaning classroom areas both at the start and the end of any class where food is made and/or consumed.

$+\quad$ Washing hands and keeping long hair back during any class where food is made and/or consumed.

$+\quad$ If you are not-so-sick-so-as-to-miss-class but sick-enough (ex: sniffles) you will excuse yourself from the food preparation and handling portion of any class or homework and contribute in other ways (recording notes, for example).

+ Special note - allergies and eating. Please remember that while you are not required to eat certain foods as part of the course, it will be a strongly encouraged option to enhance the educational experience. Please inform Dr. Vigeant (and relevant classmates) immediately if you have any allergies or sensitivities to materials being used in class.

\section{Grading:}

Class Participation (including in-class activities, before-class set-up and post-class clean-up, asking questions in and before class, and in-class problems): $20 \%$

Unit reports (initial report, questions/notebook, mini-homeworks, final report - 5 of these): $50 \%$

Small presentations (What's that stuff? and In good company - 2 of these): $10 \%$ Final Project: $20 \%$

Class participation: Class will not only include discussion and problem work, but also "lab" (cooking) during class time. Active participation in all aspects is expected, and each student is expected to help wash the dishes at least once during the semester.

Unit reports: There are five "problems" in the class, constructed to give us an opportunity to study 5 key areas of food process. Each problem will be worth $10 \%$ of your final grade, and will largely be tackled as a team. You will be responsible for an initial report (involves cooking), a final report (may involve more cooking) as a team, and then answers to class questions as an individual. You will also have in-class, smaller homework, and oral report responsibilities for some of the projects.

Small presentations: You and your teammate will be asked to give two topical presentations 
of $\sim 10-15$ minutes (plus questions) during the semester. One will be on an unusual ingredient ("what's that stuff?") and the other will focus on a company within the food industry ("in good company?"). These assignments are designed to familiarize your with the employment and engineering landscape in this important area.

Final project: The final project "Entrepreneurial Freestyle Food" you will be asked to propose a novel food product and the engineering and business architecture that would be needed to support it.

Students enrolled in the 672 section of the course will be expected to take the lead on projects, to go first for presentations, and to participate actively in clean-up and set-up duties.

\section{Course Schedule:}

Typical schedule will run on a two week cycle:

Day 0 - Project assigned. Typically it will be "Propose a process to make food $\mathrm{x}$ on a particular scale."

Day 1 homework - Experimental homework on the food under discussion; proposal of lecture topics.

Day 1-3 - Discussion of homework and lectures and small experiments on topics requested by the class, in addition to in-class project work time.

Day 4 - Sharing of reports, start of next project.

This schedule is subject to change based on interest, availability, and other possibly unpredictable elements. Further, we have several tentative guest lectures and field trips that will shift classes. Insofar as is possible, I will try to schedule several relevant field trips. Ideally, these will happen during class time, but may run over.

\section{Catch-all final statement:}

This is a new class, and both the content and format will evolve as we work together. If you have ideas or requests, tell Dr. Vigeant. We can shift things around to create the optimal learning environment for the entire group. Appendix A - Course Syllabus 